\title{
Intrinsic self-healing polymers with a high E-modulus based on dynamic reversible urea bonds
}

\author{
Stefan Zechel ${ }^{1,2}$, Robert Geitner ${ }^{3,4}$, Marcus Abend ${ }^{1,2}$, Michael Siegmann ${ }^{3,4}$, Marcel Enke ${ }^{1,2}$, Natascha Kuhl ${ }^{1,2}$, \\ Moritz Klein ${ }^{5}$, Jürgen Vitz ${ }^{1,2}$, Stefanie Gräfe ${ }^{3,4}$, Benjamin Dietzek ${ }^{2,3,4,5}$, Michael Schmitt ${ }^{3,4}$, Jürgen Popp ${ }^{2,3,4,5}$, \\ Ulrich S Schubert ${ }^{1,2}$ and Martin D Hager ${ }^{1,2}$
}

The straightforward synthesis of a urea polymer network is presented. Commercially available monomers are polymerized using light-induced polymerization, resulting in networks crosslinked by hindered urea molecules. These moieties are reversible and, thus, can be converted into the starting compounds (that is, isocyanate and amine) by a simple thermal treatment. This process is monitored using differential scanning calorimetry as well as Raman and infrared spectroscopy. Furthermore, the self-healing ability of these polymer networks is investigated using scratch-healing tests as well as bulk-healing investigations using tensile testing. The resultant materials have a high $E$-modulus, are able to heal scratches at temperatures above $70^{\circ} \mathrm{C}$ multiple times and their mechanical properties can be partially regenerated. The underlying healing mechanism is based on the reversible opening of the urea bonds and exchange reactions between two functional groups, which were confirmed from a spectroscopic analysis. In summary, these new materials are a new type of intrinsically healable polymers and provide a first step toward hard and healable polymers.

NPG Asia Materials (2017) 9, e420; doi:10.1038/am.2017.125; published online 18 August 2017

\section{INTRODUCTION}

The limited availability of natural resources is gradually causing modern society to develop more sustainable uses of oil-based materials. In particular, healing abilities in damaged materials such as polymers can increase the lifetime of such systems as these materials are able to recover their original (mechanical) properties. ${ }^{1,2}$ However, special polymer designs are required to obtain this behavior. Generally, self-healing polymers can be divided into extrinsic and intrinsic self-healing polymers. Extrinsic self-healing materials are based on the encapsulation of a healing agent (for example, in microcapsules) within the polymer matrix, which is released after cracking. ${ }^{3-5}$ In contrast, intrinsic self-healing materials can recover their properties due to the presence of specific reversible chemical bonds, which is beneficial due to the possibility of multiple healing steps at the same location. ${ }^{6}$ These binding motifs can be composed of either dynamic covalent bonds, ${ }^{7-9}$ for example, the Diels-Alder reaction ${ }^{10-12}$ or radical-based systems, ${ }^{13}$ or supramolecular interactions, such as hydrogen or halogen bonds, ${ }^{14-16}$ ionic interactions, ${ }^{17} \pi-\pi$ interactions, ${ }^{18}$ host-guest interactions ${ }^{19}$ or metal-ligand interactions. ${ }^{20-23}$ Often there is a trade-off between the mechanical properties and the healing efficiency (Figure 1). High healing efficiencies are mostly only possible for low E-moduli; for $E$-moduli above $10^{7}-10^{8} \mathrm{~Pa}$, the number of reported examples decreases significantly, as well as the achieved healing efficiencies.

Two interesting industrial polymer classes are polyurethanes and polyureas. Those materials can be easily produced by the reaction of an isocyanate with an alcohol or amine. Thus, imparting those polymers with healing abilities is a highly relevant industrial topic. Consequently, polyurethanes and polyureas have already been utilized for designing self-healing polymers. ${ }^{15}$

Polyurethanes and polyureas can also be applied for designing intrinsically healable polymers as those polymers feature hydrogen bonds. ${ }^{24-26}$ These weak bonds are highly dynamic ${ }^{27}$ and, thus, can be utilized for designing intrinsic self-healing materials. ${ }^{10}$ In particular, Leibler and his group demonstrated the self-healing effects caused by dynamic hydrogen bonds. ${ }^{15}$ Furthermore, the shape-memory effect of polyurethanes can be utilized to enhance the self-healing behaviors of polymers, which has been described as shape-memory-assisted selfhealing. ${ }^{28-30}$

One intriguing feature of sterically hindered ureas is the reversibility of the formed urea bonds. ${ }^{31,32}$ During thermal treatment or exposure to water, reversible reactions can be observed in which the isocyanate and its corresponding co-reactant are reformed. ${ }^{33,34}$ This reversibility has been well investigated in solution but has, to the best of our

\footnotetext{
${ }^{1}$ Laboratory of Organic and Macromolecular Chemistry (IOMC), Friedrich Schiller University Jena, Jena, Germany; ${ }^{2}$ Jena Center for Soft Matter (JCSM), Friedrich Schiller University Jena, Jena, Germany; ${ }^{3}$ Institute for Physical Chemistry, Friedrich Schiller University Jena, Jena, Germany; ${ }^{4}$ Abbe Center of Photonics, Friedrich Schiller University Jena, Jena, Germany and ${ }^{5}$ Leibniz Institute for Photonic Technology (IPHT) Jena, Jena, Germany

Correspondence: Professor US Schubert, Laboratory for Organic and Macromolecular Chemistry (IOMC), Friedrich Schiller University Jena, Philosophenweg 7, 07743 Jena, Germany.

E-mail: ulrich.schubert@uni-jena.de

or Dr MD Hager, Laboratory for Organic and Macromolecular Chemistry (IOMC), Friedrich Schiller University Jena, Humboldtstrasse 10, 07743 Jena, Germany.

E-mail: martin.hager@uni-jena.de

Received 21 December 2016; revised 13 March 2017; accepted 1 April 2017
} 


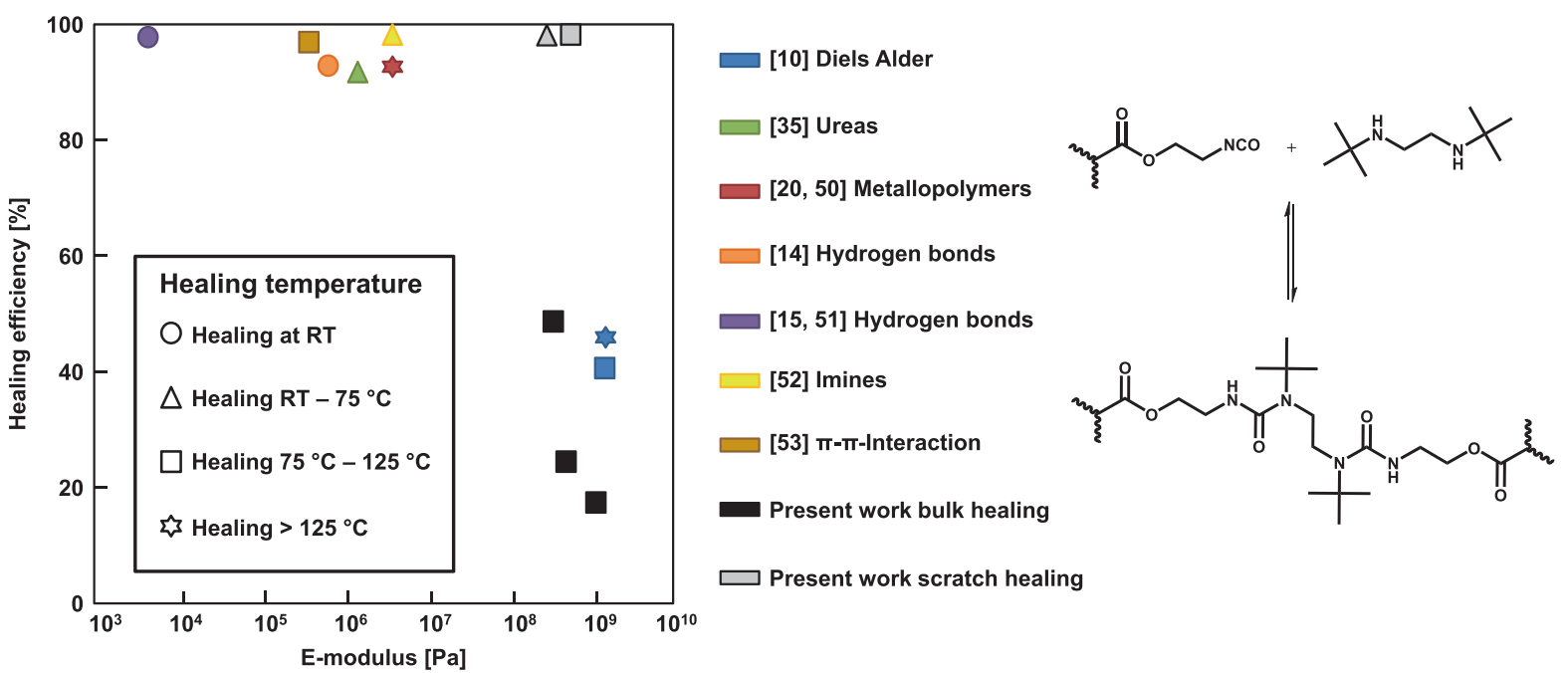

Figure 1 Schematic representation of the material properties from the literature for known intrinsically healable polymers compared with the novel polymers presented here (left) and the reversible reaction of the sterically hindered amine with an isocyanate-functionalized polymer (right).

knowledge, only been utilized once for designing a self-healing material. In that case, Cheng and co-workers presented a poly (urea-urethane) that was able to self-heal due to the reversibility of the dynamic urea bonds. ${ }^{35}$ Nevertheless, the investigated substances were soft materials with poor mechanical properties (a Young's modulus of ca. $1 \mathrm{MPa}$ at room temperature). The follow-up study by the same authors described an improvement in the mechanical properties by using a denser polymer network, which could be completely depolymerized under thermal treatment, resulting in the formation of the educts. ${ }^{36}$ Consequently, remendability as well as recyclability of the polymer network was possible. However, this behavior was associated with the nearly complete depolymerization of the network and, thus, a (partial) decrease in the mechanical integrity of the material.

In the present study, we investigate the reversibility of dynamic poly (methacrylate) systems crosslinked with dynamic urea moieties and their corresponding self-healing properties. The networks consist of commercially available substances. Furthermore, a sterically hindered amine is utilized during polymerization due to its ability to open urea bonds during thermal treatment. The polymer network is obtained after a simple photopolymerization procedure. The mechanical properties are investigated using tensile testing. Hard materials with improved mechanical and self-healing properties are obtained (Figure 1), which are novel properties for an intrinsically healable polymer. Compared to other known intrinsic self-healing polymers, a relatively high $E$-modulus is obtained combined with a rather high healing efficiency, which has not been described in the literature so far. For the first time, the dynamic character of the urea bonds in the solid state is confirmed using differential scanning calorimetry (DSC) and Raman and infrared (IR) spectroscopy. These results enable new mechanistic insights into the self-healing behavior of these materials.

\section{MATERIALS AND METHODS}

All used chemicals were purchased from VWR (Darmstadt, Germany), Aldrich (Taufkirchen, Germany) and TCI (Zwijndrecht, Belgium). They were used without further purification. Butyl methacrylate (BMA) was passed over a short aluminum oxide plug. Toluene was dried by refluxing over sodium/benzophenone. The reaction progress was monitored using thin-layer chromatography with aluminum sheets precoated with silica gel $60 \mathrm{~F}_{254}$ (Merck, Darmstadt, Germany).

One-dimensional $\left({ }^{1} \mathrm{H},{ }^{13} \mathrm{C}\right)$ nuclear magnetic resonance spectra were recorded using a Bruker (Rheinstetten, Germany) AC $300(300 \mathrm{MHz})$ at $298 \mathrm{~K}$. The chemical shifts are reported in parts per million (p.p.m., $\delta$ scale) relative to the residual signal of the solvent. The coupling constants are given in hertz.

Elemental analyses were performed using a Vario El III (Elementar, Langensebold, Germany) elemental analyzer.

A thermogravimetric analysis was carried out under nitrogen using a Netzsch (Selb, Germany) TG 209 F1 Iris, and DSC was performed using a DSC 204 F1 Phoenix from Netzsch under a nitrogen atmosphere with a heating rate of 10 or $20 \mathrm{~K} \mathrm{~min}^{-1}$.

Size-exclusion chromatography measurements were performed using the following setup: a Shimadzu (Jena, Germany) SCL-10A VP (system controller); a DGU-14A (degasser); an LC-10AD VP (pump); an SIL-10AD VP (auto sampler); an SPD-10AD VP (ultraviolet detector); an RID-10A (refractive index detector); a PSS GRAM guard/1000/30 $\AA$ (column); $N, N$-dimethylacetamide $+0.21 \% \mathrm{LiCl}$ (eluent); a $1 \mathrm{ml} \mathrm{min}^{-1}$ flow rate at $40^{\circ} \mathrm{C}$; and poly(methyl methacrylate) (standard).

The scratch-healing experiments were carried out using the optical microscope of an atomic force microscopy setup. The scratches in the material were created using a Feather disposable scalpel no. 11 (stainless steel). The investigation of the self-healing behavior started at $100^{\circ} \mathrm{C}$. If the material revealed self-healing properties, multiple scratch-healing tests at the same temperature and position were performed. Afterwards, the temperature was reduced in $10 \mathrm{~K}$ intervals until no further self-healing was observed. The bulk healing was performed at $100^{\circ} \mathrm{C}\left(\mathbf{P} 1\right.$ and P2) and at $120^{\circ} \mathrm{C}(\mathbf{P} 3)$ for $72 \mathrm{~h}$. Afterwards, annealing at the same temperature was performed for $72 \mathrm{~h}$.

Tensile tests were performed using a standard tensile machine (Z020, Zwick/Roell, Ulm, Germany) at room temperature or at $100^{\circ} \mathrm{C}$ (error $\pm 10 \mathrm{~K}$ ) with a speed of $2 \mathrm{~mm} \mathrm{~min}^{-1}$. The specimens were $5 \mathrm{~mm}$ high, $30 \mathrm{~mm}$ long and $5 \mathrm{~mm}$ wide. For each measurement condition, five different specimens were synthesized, and the average values were determined and listed in Table 3 due to the variations in each specimen.

All dynamic mechanical thermal analysis experiments were performed using an MCR 301 rheometer from Anton Paar (Ostfildern-Scharnhausen, Germany) with a convection temperature device (CTD 450) that covered a broad temperature range from -100 to $450^{\circ} \mathrm{C}$. The test specimens were $12.5 \mathrm{~mm} \times 28.5 \mathrm{~mm} \times 4 \mathrm{~mm}$, which were polymerized in a special Teflon mold and mounted into the solid rectangular fixture of the device for dynamic mechanical thermal analysis measurements under torsion. The instrument was operated with a sample gap of $20 \mathrm{~mm}$ and a frequency of $1 \mathrm{~Hz}$ with a $0.1 \%$ strain. The sample was cooled to $25^{\circ} \mathrm{C}$, and the measurements were conducted during a warm-up cycle to $140^{\circ} \mathrm{C}$. Furthermore, the frequency dependency was investigated by keeping the temperature constant at 80,100 and $120^{\circ} \mathrm{C}$. The frequency was varied from 0.1 to $100 \mathrm{~Hz}$.

The Fourier transform-IR (FT-IR) spectra of polymer P2 on a sodium chloride crystal and of compound 1 (a potassium bromide pellet) were 
Table 1 Summary of the amounts of the utilized chemicals for the polymer preparation

\begin{tabular}{lcccc}
\hline Polymer & $m(B M A)(\mathrm{mg})$ & $m$ (Amine) $(\mathrm{mg})$ & m(2-lsocyanato-ethyl methacrylate) $(\mathrm{mg})$ & $m$ (Benzoin methyl ether) $(\mathrm{mg})$ \\
\hline P1 & $999(7.03 \mathrm{mmol})$ & $30(0.17 \mathrm{mmol})$ & $55(0.35 \mathrm{mmol})$ & $3(0.01 \mathrm{mmol})$ \\
P2 & $498(3.50 \mathrm{mmol})$ & $30(0.17 \mathrm{mmol})$ & $56(0.36 \mathrm{mmol})$ & $2(0.01 \mathrm{mmol})$ \\
P3 & $501(3.52 \mathrm{mmol})$ & $149(0.86 \mathrm{mmol})$ & $276(1.78 \mathrm{mmol})$ & $4(0.02 \mathrm{mmol})$ \\
\hline
\end{tabular}

Abbreviation: BMA, butyl methacrylate.

recorded using a commercial Varian (now Agilent, Santa Clara, CA, USA) 670IR FT-IR spectrometer equipped with a deuterated triglycine sulfate detector. The FT-IR spectra were recorded between $400\left(\right.$ P2) or $700(1)$ and $4000 \mathrm{~cm}^{-1}$ with a spectral resolution of $4 \mathrm{~cm}^{-1}$. The sample temperature was adjusted using a Linkam stage LTS 350 (Linkam, Tadworth, UK). The FT-IR spectra of 1 were recorded at room temperature and at $100^{\circ} \mathrm{C}$, while the FT-IR spectra of P2 were recorded at $30,50,75,100,125,150$ and $175^{\circ} \mathrm{C}$. The heating rate was $30{ }^{\circ} \mathrm{C} \mathrm{min}{ }^{-1}$. The FT-IR spectra of a pure sodium chloride crystal and a pure potassium bromide pellet were recorded at the measurement temperatures and utilized as background spectra. The FT-IR spectra consist of 32 (1) or 64 (P2) single spectra, respectively. The sodium chloride crystal contained small amounts of liquid water on the surface, which evaporated at elevated temperatures. Thus, the FT-IR spectra slightly changed in the region between $\sim 1600$ and $3400 \mathrm{~cm}^{-1}$ due to the evaporating water. The raw FT-IR data were preprocessed using R 3.3.2 software. ${ }^{37}$ First, the FT-IR spectra were restricted to the wavenumber region of interest, that is, the region between 700 and $3125 \mathrm{~cm}^{-1}$. Subsequently, the FT-IR data were baseline corrected using a SNIP algorithm ${ }^{38}$ (iterations $=150$, order $=2$ and smoothing window $=3$ ) and the area normalized to the IR peaks between 2750 and $3100 \mathrm{~cm}^{-1}$ (1).

Furthermore, the FT-Raman spectra of the model compounds $N, N^{\prime}$-ditert-butyl-ethylenediamine, hexyl isocyanate, BMA, poly(butyl methacrylate) (PBMA), benzoin methyl ether, $\mathbf{1}$ and $\mathbf{2}$ as well as the annealed polymers $\mathbf{P 1}$ and $\mathbf{P} 2$ were measured. To confirm that Raman spectroscopy was suited to monitor the polymerization and crosslinking process, eight BMA-PBMA mixtures ( $\times(\mathrm{BMA}): 0.119 ; 0.218 ; 0.373 ; 0.472 ; 0.624 ; 0.765 ; 0.877$; and $0.950)$ as well as five mixtures of compound 1 with PBMA $(\times(\mathbf{1})$ : 0.012 ; 0.023 ; 0.053; 0.100; and 0.180 ) were prepared. One BMA-PBMA mixture was additionally spiked with compound 1 ( $\times(\mathrm{BMA}): 0.108 ; \times(\mathbf{1}): 0.092)$ to evaluate its influence on the concentration evaluation procedure. The FT-Raman spectra were recorded up to $3600 \mathrm{~cm}^{-1}$ with a spectral resolution of $4 \mathrm{~cm}^{-1}$ using a commercial Bruker MultiSpec spectrometer. Raman excitation light at $1064 \mathrm{~nm}$ was provided by a Nd:YAG laser (Klastech DeniCAFC-LC-3/40, Klastech, Dortmund, Germany). The laser power at the samples was $400 \mathrm{~mW}$. The FT-Raman spectra were recorded using the OPUS 6.5 software package (Bruker Optics in Ettlingen, Germany). The spectra of $N$, $N^{\prime}$-di-tert-butyl-ethylenediamine, hexyl isocyanate, 1 and 2 consisted of 724 single spectra, while the spectra of benzoin methyl ether, $\mathbf{P} 1$ and $\mathbf{P} 2$ consisted of 512 single spectra. For BMA, PBMA, 1 and the different mixtures, 16 spectra consisting of 32 single spectra were recorded.

The raw Raman spectra were preprocessed and analyzed using R (3.3.2). ${ }^{37}$ First, the Raman spectra were restricted to the wavenumber region of interest, that is, the region between 250 and $3500 \mathrm{~cm}^{-1}$. Subsequently, the Raman data were background-corrected using a SNIP algorithm ${ }^{38}$ (iterations $=100$, order $=$ 2 and smoothing window $=3$ ) and normalized to the Raman peaks at $2924 \mathrm{~cm}^{-1}$ (hexyl isocyanate), $2972 \mathrm{~cm}^{-1}$ ( $N, N^{\prime}$-di-tert-butylethylenediamine), $2929 \mathrm{~cm}^{-1}$ (1), $2931 \mathrm{~cm}^{-1}$ (2) and $2926 \mathrm{~cm}^{-1}$ (P2).

To determine whether Raman spectroscopy was suited to follow the polymerization and crosslinking process, the wavenumber-restricted and background-corrected spectra of BMA, PBMA, 1, the nine BMA-PBMA mixtures and the five mixtures of 1 with PBMA were area-normalized to the peak at $1451 \mathrm{~cm}^{-1}$ (integrated from 1420 to $1490 \mathrm{~cm}^{-1}$ ). This peak was attributed to $\mathrm{CH}$ deformation vibrations, which should have been similar for all studied substances. To follow the polymerization process, three Raman peaks were monitored: the $\mathrm{C}=\mathrm{C}$ stretching vibration stemming from BMA at $1641 \mathrm{~cm}^{-1}$ (integrated from 1610 to $1667 \mathrm{~cm}^{-1}$ ), the $=\mathrm{C}-\mathrm{H}$ stretching vibration stemming from BMA at $3107 \mathrm{~cm}^{-1}$ (integrated from 3080 to $3140 \mathrm{~cm}^{-1}$ ) and the $=\mathrm{C}-\mathrm{H}$ deformation vibration also stemming from BMA at $1404 \mathrm{~cm}^{-1}$ (integrated from 1385 to $1420 \mathrm{~cm}^{-1}$ ). To monitor the urea content, the $\mathrm{C}=\mathrm{O}$ stretching vibration at $1631 \mathrm{~cm}^{-1}$ (integrated from 1614 to $1654 \mathrm{~cm}^{-1}$ ) was used. Linear models were built using the mole fractions of BMA or compound $\mathbf{1}$ and the corresponding integrated band area (Supplementary Information; Supplementary Figures S39-S41). Using the described approach, the limit of detection for the BMA inside PBMA was $\sim 5 \mathrm{~mol} \%$, while the limit of detection for compound 1 inside PBMA was $\sim 2 \mathrm{~mol} \%$. The limit of detection was calculated using the respective peak area $+3 \times$ the s.d. of the peak area extracted from the Raman spectra of the pure PBMA. It is important to note that the simultaneous identification of BMA and 1 inside PBMA was possible. First, the BMA mole fraction was evaluated using the peak at $3107 \mathrm{~cm}^{-1}$, and after, the urea mole fraction was analyzed by integrating the overlapped peak at $\sim 1635 \mathrm{~cm}^{-1}$ and subtracting the contribution of the afore-calculated BMA mole fraction (Supplementary Figures S39-S41).

To further investigate the self-healing mechanism of the present class of polymers and to validate the band assignments, quantum chemical calculations were performed. To reduce the computational demand, only the monomers $N, N^{\prime}$-di-tert-butylethylenediamine, hexyl isocyanate, 2-isocyanatoethyl methacrylate, $\mathbf{1}$ and $\mathbf{2}$ were considered. All quantum chemical simulations were performed using DFT with the global hybrid functional B3LYP ${ }^{39,40}$ and the $6-31+G(d, p)$ double- $\zeta$ basis set ${ }^{41,42}$ implemented in the Gaussian 09 program. ${ }^{43}$ The fully relaxed equilibrium structures of $N, N^{\prime}$-di-tert-butyl-ethylenediamine, hexyl isocyanate, 2-isocyanatoethyl methacrylate, $\mathbf{1}$ and $\mathbf{2}$ were obtained, while the subsequent vibrational analysis determined the minima of the $3 N-6$ dimensional potential energy (hyper)surfaces as well as the vibrational frequencies and IR and Raman intensities. To account for anharmonicity and the lack of electronic correlation, the frequencies were scaled by a factor of $0.964{ }^{44,45}$ The calculated IR and Raman spectra were preprocessed (wavenumber region restriction, baseline/background correction and normalization) to make them comparable to the experimental IR and Raman spectra.

\section{Experimental procedures}

Synthesis of the model compound and the monomer. 1-1'-(Ethane-1,2-diybis (1-tert-butyl)-3-hexylurea) (1): Hexyl isocyanate $(2.30 \mathrm{ml} ; 15.79 \mathrm{mmol})$ and $0.1 \mathrm{ml}$ of dibutyltin dilaurate $(0.17 \mathrm{mmol})$ were dissolved in $20 \mathrm{ml}$ of dry toluene under nitrogen atmosphere. Subsequently, $1.7 \mathrm{ml}$ of $N, N$ '-di-tert-butylethylenediamine $(7.88 \mathrm{mmol})$ was added slowly over $15 \mathrm{~min}$. Afterwards, the reaction mixture was stirred at room temperature for $18 \mathrm{~h}$. The solvent was removed, and the residual solid was dissolved in $200 \mathrm{ml}$ of chloroform. The organic layer was washed with water $(2 \times 200 \mathrm{ml})$ and dried over sodium sulfate. After filtration and evaporation of the solvent, a white product was obtained.

Yield: $2.10 \mathrm{~g}$ of a white solid (89\%).

Melting point: $98^{\circ} \mathrm{C}$.

${ }^{1} \mathrm{H}$ NMR $\left(300 \mathrm{MHz}, \mathrm{CDCl}_{3}\right): \delta=0.81\left(\mathrm{t}, 6 \mathrm{H},-\mathrm{CH}_{3}, J=6.6 \mathrm{~Hz}\right) ; 1.20-1.47$ (m, 34H, tert-butyl, $\mathrm{CH}_{2}$-alkyl); $3.12\left(\mathrm{q}, 4 \mathrm{H}, \mathrm{NH}-\mathrm{CH}_{2}, J=5.4 \mathrm{~Hz}\right) ; 3.20$ (s, $4 \mathrm{H}, \mathrm{N}-\mathrm{CH}_{2}$ ); and $5.88(\mathrm{t}, 2 \mathrm{H}, \mathrm{NH}, J=5.4 \mathrm{~Hz})$ p.p.m.

${ }^{13} \mathrm{C}$ NMR $\left(75 \mathrm{MHz}, \mathrm{CDCl}_{3}\right): \delta=14.0 ; 22.6 ; 26.6 ; 26.8 ; 29.6 ; 30.1 ; 30.3 ; 31.6$; 40.5; 40.8; 47.3; 55.0; and 160.2 p.p.m.

Anal. calcd for $\mathrm{C}_{24} \mathrm{H}_{50} \mathrm{~N}_{4} \mathrm{O}_{2}$ : C 67.56, $\mathrm{H} 11.81$ and N 13.13; found: C 67.61, $\mathrm{H} 11.67$ and $\mathrm{N} 12.84$.

FT-IR (KBr): $\tilde{\mathrm{v}}=3304(\mathrm{~m}, \nu(\mathrm{N}-\mathrm{H})) ; 2956(\mathrm{~m}, \nu(\mathrm{C}-\mathrm{H})) ; 2928(\mathrm{~m}, \nu(\mathrm{C}-\mathrm{H}))$; 2861 (w, $v(\mathrm{C}-\mathrm{H})$ ); 1626 (vs, $\nu(\mathrm{C}=\mathrm{O})$ ); 1531 (m, amide II); 1479 (vw, $\delta(\mathrm{CH})$ ); $1387(\mathrm{vw}) ; 1363(\mathrm{w}) ; 1342(\mathrm{w}) ; 1300(\mathrm{vw}) ; 1250(\mathrm{w}) ; 1197(\mathrm{w}) ; 1149(\mathrm{vw}) ;$ $1028(\mathrm{vw}) ; 799(\mathrm{vw})$; and $771(\mathrm{vw}) \mathrm{cm}^{-1}$. 
FT-Raman $(1064 \mathrm{~nm}, \mathrm{~s}): \tilde{\mathrm{v}}=3293(\mathrm{vw}, \mathrm{v}(\mathrm{N}-\mathrm{H})) ; 3015(\mathrm{w}, \mathrm{v}(\mathrm{C}-\mathrm{H})) ; 2969$ (s, $\nu(\mathrm{C}-\mathrm{H})$ ); 2929 (vs, $\nu(\mathrm{C}-\mathrm{H})$ ); 2893 (vs, $\nu(\mathrm{C}-\mathrm{H})$ ); 2862 (vs, $\nu(\mathrm{C}-\mathrm{H})$ ); 2776 $(\mathrm{vw}, v(\mathrm{C}-\mathrm{H})) ; 2715$ (vw, $v(\mathrm{C}-\mathrm{H})) ; 1630(\mathrm{vw}, \nu(\mathrm{C}=\mathrm{O})) ; 1519$ (vw, amide II); 1451 (m, $\delta(\mathrm{CH})$ ); 1382 (vw); $1336(\mathrm{vw}) ; 1301$ (vw); 1248 (vw); 1223 (vw); 1150 (vw); 1129 (vw); 1067 (vw); 1033 (vw); 1010 (vw); 976 (vw); 921 (vw); 893 (vw); 861 (vw); 819 (vw); 796 (vw); 747 (vw); 704 (vw); 555 (vw); 511 (vw); $434(\mathrm{vw})$; and $327(\mathrm{vw}) \mathrm{cm}^{-1}$.

5,8-Di-tert-butyl-4,9-dioxo-3,5,8,10-tetraazadodecane-1,12-diyl bis(2-methylacrylate) (2): 2-Isocyanatoethyl methacrylate $(1.85 \mathrm{ml} ; 13.09 \mathrm{mmol})$ and $0.1 \mathrm{ml}$ of dibutyltin dilaurate $(0.17 \mathrm{mmol})$ were dissolved in $20 \mathrm{ml}$ of dry toluene under a nitrogen atmosphere. Subsequently, $1.4 \mathrm{ml}$ of $N, N^{\prime}$-di-tert-butylethylenediamine $(6.49 \mathrm{mmol})$ was added slowly over $15 \mathrm{~min}$. Afterwards, the reaction mixture was stirred at room temperature for $36 \mathrm{~h}$. The solvent was removed, and the residual solid was dissolved in $150 \mathrm{ml}$ of chloroform. The organic layer was washed with water $(3 \times 100 \mathrm{ml})$ and dried over sodium sulfate. After filtration and evaporation of the solvent, a white product was obtained.

Yield: $2.06 \mathrm{~g}$ of a white solid (97\%).

Melting point: $93^{\circ} \mathrm{C}$.

${ }^{1} \mathrm{H} \quad \mathrm{NMR} \quad\left(300 \mathrm{MHz}, \quad \mathrm{CDCl}_{3}\right): \delta=1.34 \quad(\mathrm{~s}, \quad 18 \mathrm{H}$, tert-butyl); 1.87 (s, $\left.6 \mathrm{H},-\mathrm{CH}_{3}\right) ; 3.20\left(\mathrm{~s}, 4 \mathrm{H}, \mathrm{N}-\mathrm{CH}_{2}\right) ; 3.45\left(\mathrm{q}, 4 \mathrm{H}, \mathrm{NH}-\mathrm{CH}_{2}, J=5.4 \mathrm{~Hz}\right) ; 4.19$ (q, $\left.4 \mathrm{H}, \mathrm{O}-\mathrm{CH}_{2}, J=5.4 \mathrm{~Hz}\right) ; 5.49\left(\mathrm{~s}, 2 \mathrm{H},=\mathrm{CH}_{2}\right) ; 6.06\left(\mathrm{~s}, 2 \mathrm{H},=\mathrm{CH}_{2}\right)$; and $6.18(\mathrm{t}, 2 \mathrm{H}, \mathrm{NH}, J=5.4 \mathrm{~Hz})$ p.p.m.

${ }^{13} \mathrm{C}$ NMR $\left(75 \mathrm{MHz}, \mathrm{CDCl}_{3}\right): \delta=18.3 ; 29.9 ; 40.0 ; 46.1 ; 54.7 ; 64.1 ; 125.6$; 136.2; 159.3; and 167.7 p.p.m.

Anal. calcd for $\mathrm{C}_{24} \mathrm{H}_{42} \mathrm{~N}_{4} \mathrm{O}_{6}$ : C 59.73, H 8.77 and N 11.24; found: $\mathrm{C} 60.01, \mathrm{H}$ 9.07 and $\mathrm{N} 11.24$.

FT-Raman $(1064 \mathrm{~nm}, \mathrm{~s}): \tilde{\mathrm{v}}=3401(\mathrm{vw}, \nu(\mathrm{N}-\mathrm{H})) ; 3113(\mathrm{vw}, \nu(=\mathrm{C}-\mathrm{H}))$; 2989 (m, v(C-H)); 2969 (m, v(C-H)); 2930 (vs, $v(\mathrm{C}-\mathrm{H})$ ); 2891 (m, v(C-H)); $2783(\mathrm{vw}, \nu(\mathrm{C}-\mathrm{H})) ; 2710(\mathrm{vw}, \nu(\mathrm{C}-\mathrm{H})) ; 1698(\mathrm{w}, \nu(\mathrm{C}=\mathrm{O})$ methacrylate); 1656 (sh, $v(\mathrm{C}=\mathrm{O})$ urea); $1639(\mathrm{~m}, \nu(\mathrm{C}=\mathrm{C})$ ); 1511 (vw, amide II); $1458(\mathrm{w}, \delta(\mathrm{CH})$ ); 1432 (w, $\delta(\mathrm{CH})$ ); 1409 (w); 1379 (vw); 1341 (vw); 1324 (vw); 1281 (vw); 1236 (vw); 1217 (vw); $1154(\mathrm{vw}) ; 1081(\mathrm{vw}) ; 1037(\mathrm{vw}) ; 1015$ (vw); 976 (vw); 958 (vw); 909 (vw); 893 (vw); 859 (vw); 818 (vw); 782 (vw); 738 (vw); 700 (vw); 666 (vw); 605 (vw); 543 (vw); 520 (vw); 478 (vw); 440 (vw); 384 (vw); 348 (vw); $303(\mathrm{vw})$; and $256(\mathrm{vw}) \mathrm{cm}^{-1}$.

Polymer synthesis. Benzoin methyl ether was dissolved in BMA. Subsequently, 2-isocyanatoethyl methacrylate and $N, N^{\prime}$-di-tert-butylethylenediamine were added, and the resulting solution was irradiated by a Kulzer Dentacolor (Kulzer $\mathrm{GmbH}$, Hanau, Germany) (excitation from 320 to $520 \mathrm{~nm}$ ) for $30 \mathrm{~min}$. Subsequently, the polymers were annealed for $24 \mathrm{~h}$ at $100^{\circ} \mathrm{C}$. The exact amounts are listed in Table 1, and the resulting properties are summarized in Table 2.

The polymer network $\mathbf{P} 4$ was prepared according to the literature. ${ }^{23}$ The pure PBMA, which was only utilized as a model substance for the Raman measurements, was also synthesized according to the previous literature reports. ${ }^{16}$

Dissolution experiments of $P 1$ in aniline. In a $20 \mathrm{ml}$ microwave vial, $96 \mathrm{mg}$ of P1 was suspended in $5 \mathrm{ml}$ of freshly distilled aniline. Subsequently, the mixture was heated to $100{ }^{\circ} \mathrm{C}$ for $48 \mathrm{~h}$, and the complete dissolution of the polymer was observed. An size exclusion chromatography of the solution was measured.

As a control experiment, $113 \mathrm{mg}$ of $\mathbf{P 1}$ was suspended in $5 \mathrm{ml}$ of freshly distilled aniline and stirred for $48 \mathrm{~h}$ at room temperature. In that case, polymer dissolution was not observed, and soluble polymers were not present during the SEC measurement.

Table 2 Overview of the elemental analysis results and thermal properties of polymers P1-P3

\begin{tabular}{lccccc}
\hline Polymer & Carbon (\%) & Hydrogen (\%) & Nitrogen (\%) & DSC: $\mathrm{T}_{g}\left({ }^{\circ} \mathrm{C}\right)$ & TGA: $\mathrm{T}_{d}\left({ }^{\circ} \mathrm{C}\right)$ \\
\hline P1 & 66.12 & 9.53 & 2.55 & 30 & 257 \\
P2 & 66.02 & 9.80 & 3.17 & 36 & 189 \\
P3 & 62.55 & 9.32 & 6.94 & - & 240 \\
\hline
\end{tabular}

Abbreviations: DSC, differential scanning calorimetry; TGA, thermogravimetric analysis.
SEC: $M_{\mathrm{n}}=5300 \mathrm{~g} \mathrm{~mol}^{-1}, M_{\mathrm{w}}=24800 \mathrm{~g} \mathrm{~mol}^{-1}$ and $Ð=4.69$.

\section{RESULTS AND DISCUSSION}

To obtain dynamic networks based on urea bonds, a specific monomer was synthesized. In addition, a model substance was prepared to understand the mechanism of healing. For this purpose, $N, N^{\prime}$-di-tert-butylethylenediamine, as a sterically hindered amine, was converted with either hexyl isocyanate, resulting in model compound 1, or with 2-isocyanate ethyl methacrylate, resulting in monomer 2-the reversible crosslinker. Both compounds were characterized via NMR and Raman spectroscopy (Supplementary Information; Supplementary Figures S4) to confirm the formation of urea bonds.

The prepared monomer was utilized to prepare the polymer networks. To obtain a sufficiently crosslinked system, an additional comonomer was required. Moreover, a comonomer with a relatively low glass transition temperature was desired to achieve sufficient mobility during the healing process. For this purpose, the solubility of 2 was evaluated in different commercially available comonomers. The synthesized crosslinker was not soluble in the methacrylates tested, such as BMA or lauryl methacrylate or even more polar monomers such as di(ethylene glycol) methyl ether methacrylate. Consequently, the bulk polymerization of $\mathbf{2}$ with the aforementioned comonomers was impossible. Thus, a different approach was utilized to obtain urea-crosslinked copolymers. 2-Isocyanatoethyl methacrylate and $N, N$-di-tert-butylethylenediamine were directly mixed with the corresponding comonomer, that is, BMA and benzoin methyl ether (as initiator), as shown in Scheme 1. The homogeneous mixture was polymerized, resulting in a urea-crosslinked poly(methacrylate) network. The photopolymerization process included radical polymerization of the methacrylate moieties, as well as crosslinking via the formation of reversible urea bonds. Using this procedure, three different copolymer networks were prepared. The resulting copolymers featured different concentrations of reversible urea crosslinks (P1, P2 and P3 featured 5\%, 10\% and 50\% urea crosslinks, respectively).

The presence of urea bonds, which were formed during polymerization, and the conversion of methacrylate were confirmed using Raman spectroscopy. The Raman spectrum of $\mathbf{P} 2$ is depicted in the supporting information (Supplementary Figure S35). In this context, the full conversion of the monomers (both urea formation and methacrylate polymerization) was evident from these spectra by monitoring the $\mathrm{C}=\mathrm{C}$ double bond or the $\mathrm{C}-\mathrm{H}$ stretching of the methacrylate as well as the $\mathrm{C}=\mathrm{O}$ double bond of the urea. To prove the suitability of this method, a series of concentrations of either compound $\mathbf{1}$ or BMA in PBMA was analyzed (Supplementary Information; Supplementary Figures S39-S41). Thus, the limits of detection for the nonpolymerized methacrylate and urea bonds were $5 \%$ and $2 \%$, respectively (for details of the characterization, see the experimental section; the graphs are depicted in the Supplementary Information; Supplementary Figures S39-S41). In addition, the analysis of $\mathbf{P 2}$ revealed the full conversion of the methacrylate polymerization, and furthermore, the expected urea content of $10 \%$ was also found.

Moreover, the thermal properties were measured using DSC and thermogravimetric analysis. The copolymer networks P1 and P2 featured a glass transition temperature $\left(T_{\mathrm{g}}\right)$ of ca. $30-35^{\circ} \mathrm{C}$, whereas no $T_{\mathrm{g}}$ was observed for P3. Furthermore, the copolymers were thermally stable up to $190{ }^{\circ} \mathrm{C}$. However, the thermogravimetric analysis measurements revealed a two-step degradation process, which was presumably associated with the evaporation of the amine at 


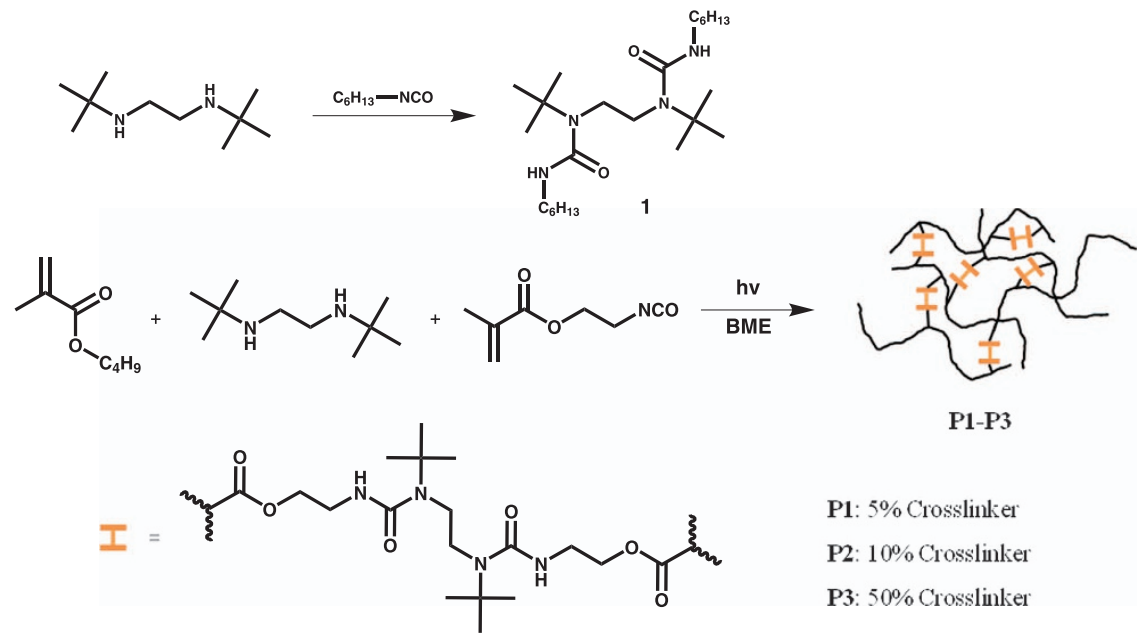

Scheme 1 Schematic representation of the synthesis of model compound 1 and copolymers P1-P3 using a photopolymerization process with benzoin methyl ether (BME) as the initiator and light between 320 and $520 \mathrm{~nm}$.

$\sim 200^{\circ} \mathrm{C}$ and, second, the complete degradation of the residual polymer (at $\sim 300^{\circ} \mathrm{C}$ ).

Furthermore, temperature-dependent rheology measurements were performed for the P1 and P2 polymer networks (Supplementary Information; Supplementary Figures S14 and S15). These data revealed softening of the polymers at temperatures above 70 (P1) and $80^{\circ} \mathrm{C}(\mathbf{P} 2)$, respectively, which present comparable behavior with vitrimers. $^{46}$

In addition to the urea-crosslinked copolymers, a polymer network featuring no reversible crosslinker was prepared (P4). This material was obtained after the bulk polymerization of BMA and 1,6-hexanediol dimethacrylate according to procedures reported in the literature. ${ }^{23}$ The degree of crosslinking was $5 \%$ and, thus, was comparable with $\mathbf{P 1}$.

The synthesized copolymer networks were investigated with respect to their self-healing behavior. For this purpose, scratch-healing tests, which are the standard technique for evaluating the healing behavior of coatings, ${ }^{47}$ were performed. These experiments revealed that copolymer network P3 did not have self-healing abilities (Supplementary Information; Supplementary Figure S3). Owing to its high crosslinking density, the flexibility of the network was significantly reduced, preventing crack closure. In contrast, the other two networks, P1 and P2, were capable of self-healing. The self-healing ability of P1 was higher (Figure 2; Supplementary Figure S1) than that of P2 (Supplementary Information; Supplementary Figure S2). In the case of P1, the scratch was healed within $10 \mathrm{~min}$ at $100^{\circ} \mathrm{C}$. To undergo scratch healing, temperatures higher than $70^{\circ} \mathrm{C}$ were required. In contrast, $\mathbf{P} 2$ required longer self-healing times $\left(60 \mathrm{~min}\right.$ at $\left.100^{\circ} \mathrm{C}\right)$ and higher temperatures $\left(>80^{\circ} \mathrm{C}\right.$ ) (Supplementary Information; Supplementary Figure S2) due to the higher crosslinking density, which reduced the overall flexibility of the polymer network. Furthermore, P4, the reference polymer without any reversible moiety, featured no scratch-healing ability, as reported in the literature. ${ }^{23}$

In addition to the scratch-healing tests, tensile testing was performed. For this purpose, the above-described bulk polymerization was performed in a Teflon mold to obtain dog bone-shaped specimens (Supplementary Information; Supplementary Figure S22). First, the mechanical properties of the three virgin polymers were studied (see Supplementary Information for the diagrams; Supplementary Figures S23-S26). The obtained average values are summarized in
Table 3. The resulting materials were rather hard compared to many other self-healing polymers (Figure 1) and featured excellent mechanical properties (E-moduli between 0.34 and $0.97 \mathrm{GPa}$ ). Such values are not obtained often for intrinsic self-healing systems, and the current materials are among the hardest intrinsically healable polymers, to the best of our knowledge, described in the literature (Figure 1). One other example of a self-healing material with a high $E$-modulus was described by Wudl and co-workers, who utilized a highly crosslinked polymer network (E-modulus: $3 \mathrm{GPa}) .{ }^{10,11}$

Subsequently, the polymers were cut into two pieces and brought back into contact. Afterwards, the specimens were heated to $100{ }^{\circ} \mathrm{C}$ to initiate the healing process. Compared to the scratch-healing process, much longer healing times were required, which was due to the poor contact between the surfaces of the cut pieces, representing a general problem during tensile testing of self-healing polymers. ${ }^{47}$ This behavior also limited the overall self-healing performance. In addition, the hardness of the material had a negative impact that could lead to reduced contact between the surfaces. To prove this assumption, the hardness of $\mathbf{P 1}$ was measured at $100{ }^{\circ} \mathrm{C}$ using tensile testing (Supplementary Information; Supplementary Figure S23). Even at high temperatures, $E$-modulus values $>1 \mathrm{MPa}$ were observed, which is a standard value of many other intrinsically healable polymers at room temperature (Figure 1). Thus, this material still featured sufficient hardness at high temperatures compared to other self-healing systems. ${ }^{10,36}$ These results indicate that neither depolymerization of the whole polymer nor complete decrosslinking occurred, which was further proven by testing the $\mathbf{P} \mathbf{4}$ reference, which featured comparable mechanical performance at both temperatures. Consequently, the mechanical integrity of the specimen was ensured. However, the mobility of the polymer network was lower compared to other very hard intrinsic self-healing polymers, indicating depolymerization behavior. As an example, the Diels-Alder polymer networks reported by Wudl and co-workers depolymerized completely during thermal treatment, resulting in a very mobile phase and, consequently, in efficient self-healing behavior. ${ }^{10}$ However, during depolymerization and formation of the educts, the mechanical integrity was (partially) lost.

Thus, these novel urea-based materials became hard materials at room temperature, and even under the healing conditions, the residual mechanical performance was good (comparable to the mechanical properties of other reported self-healing polymers at room 

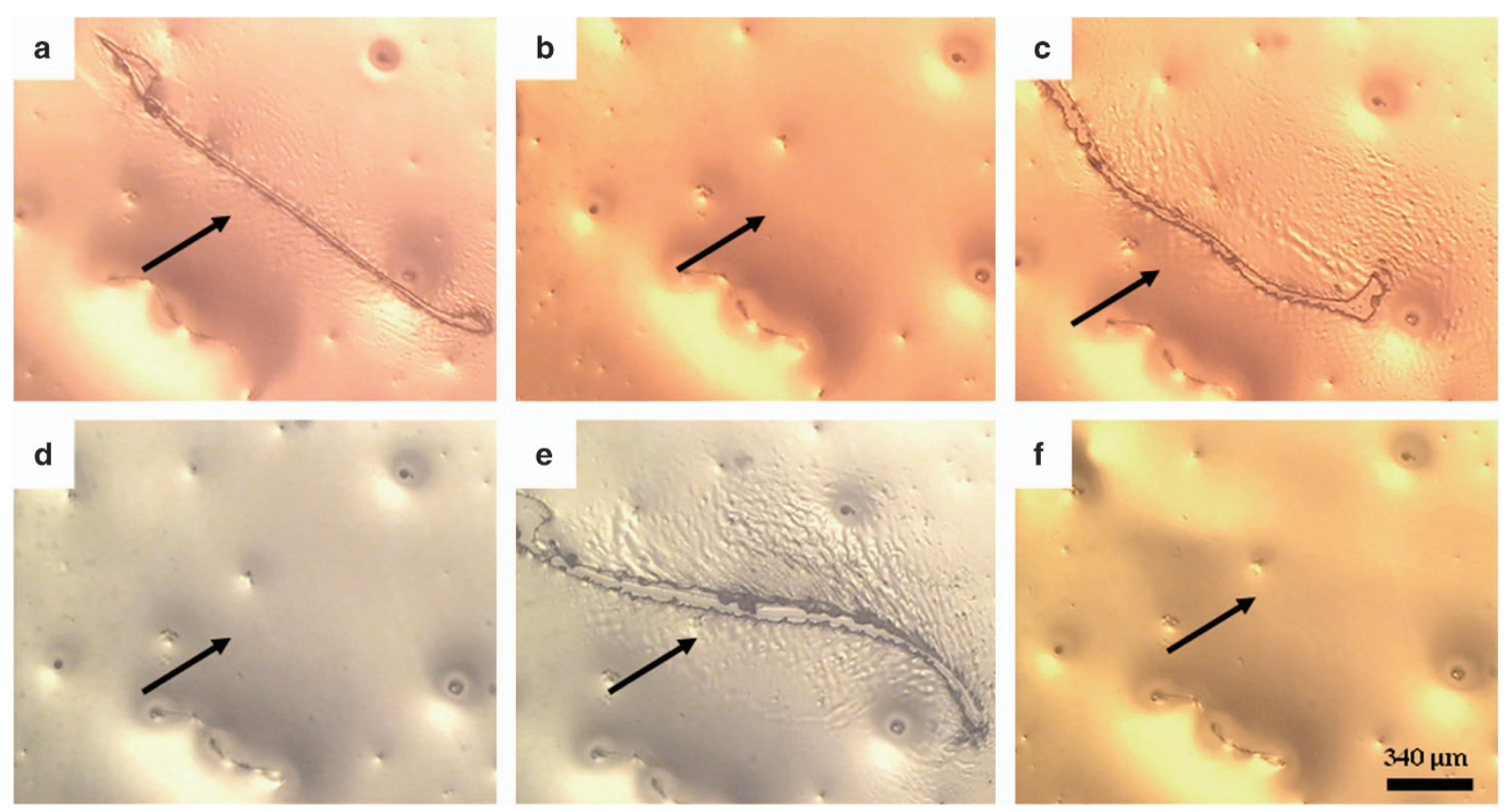

Figure 2 Time-dependent scratch-healing studies of polymer network P1: (a) first scratch; (b) healing of the first scratch after $60 \mathrm{~min}$ at $100{ }^{\circ} \mathrm{C}$; (c) second scratch; (d) second healing after $20 \mathrm{~min}$ at $100{ }^{\circ} \mathrm{C}$; (e) third scratch; and (f) third healing after $10 \mathrm{~min}$ at $100^{\circ} \mathrm{C}$.

Table 3 Summary of the mechanical properties of the polymers (P1-P4) before and after healing

\begin{tabular}{|c|c|c|c|c|c|c|}
\hline Polymer & Healed or original & Temperature $\left({ }^{\circ} \mathrm{C}\right)^{\mathrm{a}}$ & Healing conditions & E-modulus (GPa) & $\sigma_{\max }(M P a)$ & Healing efficiency \\
\hline P1 & Original & 25 & - & 0.34 & 17.3 & - \\
\hline P1 & Original & 100 & - & 0.0016 & 0.64 & - \\
\hline P1 & Healed & 25 & $72 \mathrm{~h}$ at $100^{\circ} \mathrm{C}$ & 0.32 & 8.7 & $50 \%$ \\
\hline P2 & Original & 25 & - & 0.63 & 26.4 & - \\
\hline P2 & Healed & 25 & $72 \mathrm{~h}$ at $100^{\circ} \mathrm{C}$ & 0.67 & 5.5 & $21 \%$ \\
\hline P3 & Original & 25 & - & 0.97 & 22.4 & - \\
\hline P3 & Healed & 25 & $72 \mathrm{~h}$ at $120^{\circ} \mathrm{C}$ & 0.94 & 3.5 & $16 \%$ \\
\hline P4 & Original & 25 & - & 0.35 & 14.3 & - \\
\hline P4 & Original & 100 & - & 0.010 & 0.66 & - \\
\hline
\end{tabular}

aTemperature at which the measurement was performed.

bThe self-healing efficiency was calculated by the utilization of the $\sigma_{\max }$ values.

temperature). Thus, the materials presented here are among the few intrinsically healable polymers with very good mechanical properties (Figure 1).

Nevertheless, the healing efficiency of the bulk materials was not optimal. In contrast, the E-modulus could be regenerated nearly completely. However, the healing efficiency based on the maximal stress values was $50 \%$ for P1, which is quite high for such a hard material (Table 1). Comparable hard materials were reported by Wudl et al., and the authors reported a healing efficiency of $\sim 50 \%$ even under nearly complete depolymerization of the network. ${ }^{10}$ Furthermore, there were differences in the self-healing abilities of the different copolymer networks. The highest efficiency was obtained for P1 and the lowest efficiency was obtained for the highly crosslinked P3 material. For P3, higher temperatures were required to enable bulk healing, that is, $120^{\circ} \mathrm{C}$. Furthermore, the higher degree of crosslinking also led to a harder material and thus the contact between the broken specimen was reduced, as mentioned above. ${ }^{47}$
In addition to both healing tests (the scratch-healing and tensile tests), the molecular mechanism was investigated. For this purpose, different techniques were utilized, such as DSC and Raman and IR spectroscopy. All corresponding spectra are depicted in the Supplementary Information. The polymers and model compound $\mathbf{1}$ were investigated regarding the thermal behavior. This compound featured a melting point at $98^{\circ} \mathrm{C}$, which was confirmed from the DSC measurement during the first heating run (Supplementary Information; Supplementary Figure S7). Furthermore, the compound was analyzed using FT-IR spectroscopy at different temperatures, and the urea bonds opened during thermal treatment at $100^{\circ} \mathrm{C}$. This observation was confirmed by the appearance of the specific signal of the isocyanate moiety at $2300 \mathrm{~cm}^{-1}$, proving the reversibility of the urea bonds (Figure 3). Thus, the melting of the compound at $98^{\circ} \mathrm{C}$ was associated with the opening of the reversible bonds.

The same experiment was performed with $\mathbf{P} 2$, and the resulting spectra are depicted in the Supplementary Information. In addition, 


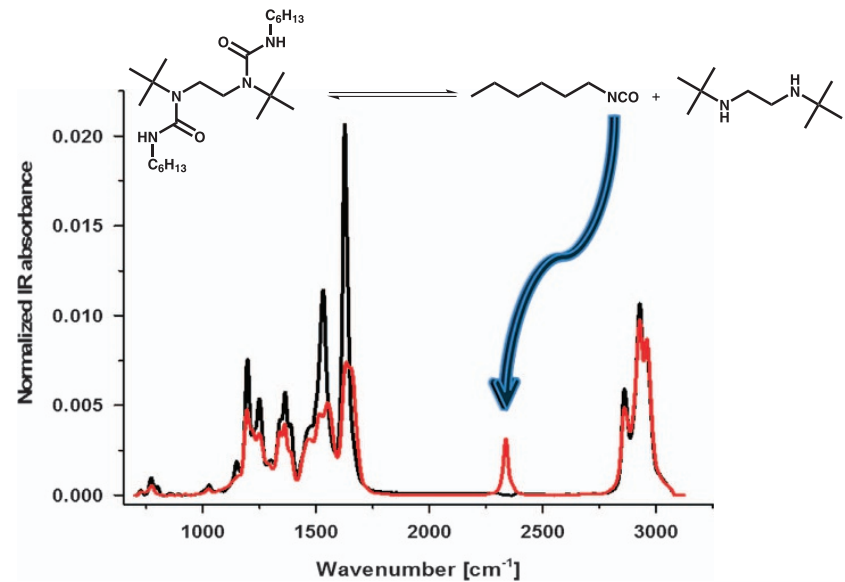

Figure 3 Temperature-dependent, baseline-corrected Fourier transform infrared spectra of compound 1 at room temperature (solid black line) and at $100{ }^{\circ} \mathrm{C}$ (solid red line). The characteristic signal of the isocyanate moiety at $2338 \mathrm{~cm}^{-1}$ was detected at $100{ }^{\circ} \mathrm{C}$.

temperature-dependent Raman spectroscopy measurements were performed. However, both analytical methods revealed no structural changes, and the spectra did not change during thermal treatment under the healing conditions. Thus, the isocyanate band was not observed. The urea-isocyanate equilibrium did not shift significantly during heating to $100^{\circ} \mathrm{C}$, as opposed to the equilibrium found for model compound 1 . As a result, the self-healing mechanism of these systems was based on reversible exchange reactions between the urea crosslinks in the copolymer network. Presumably, a small number of reversible bonds were opened during thermal treatment, but the exchange and rebinding process to other amine functionalities was too fast to detect using steady-state spectroscopic measurements. Furthermore, the absence of any changes within the Raman spectra also revealed the molecular integrity of the polymer network. However, at much higher temperatures $\left(150^{\circ} \mathrm{C}\right)$, slight bond opening was also observed in the FT-IR spectroscopy results for polymer P2 (Supplementary Information; Supplementary Figure S38).

Furthermore, frequency-dependent rheology measurements were performed at three different temperatures using polymers P1 and P2 (80, 100 and $120^{\circ} \mathrm{C}$; Supplementary Information; Supplementary Figures S16-S21). In all cases, a crossover between $G^{\prime}$ and $G^{\prime \prime}$ was observed within in the range of $0.90-24.13 \mathrm{~Hz}$ (Supplementary Information; Supplementary Table S1). Consequently, these materials featured sufficient flow at these temperatures and still revealed reversible network properties. In case of the supramolecular systems, the crossover between $G^{\prime}$ and $G^{\prime \prime}$ in a certain frequency regime could be correlated to the supramolecular bond lifetime and the self-healing properties. Thus, times in the range of $1 \mu \mathrm{s} \leqslant \tau \leqslant 60 \mathrm{~s}$ (the corresponding frequencies were $0.02-1.000 .000 \mathrm{~Hz}$ ) could be correlated to the excellent healing properties. ${ }^{17}$ Furthermore, we plotted the results of the frequency-dependent rheology measurements in a double-logarithmic plot showing that $\lim G^{\prime} \neq 0$ and $\lim G^{\prime \prime} \neq 0$. Moreover, the $G^{\prime}$ value at very low frequencies was greater than the $G^{\prime \prime}$ value. Both findings revealed the presence of the network structure at the healing temperatures, indicating that dynamic exchange reactions provided the healing mechanism. ${ }^{48}$

In addition, these findings could also be observed within the DSC measurements. In contrast to model compound 1, an endothermic signal at $100{ }^{\circ} \mathrm{C}$ was not observed for polymers P1-P3. Furthermore, the temperature-dependent mechanical performance of P1 (in particular, compared to P4) proves this hypothesis, as complete opening of the bonds would have resulted in an enormous loss in the mechanical performance. Thus, the self-healing mechanism was presumably based on exchange reactions between the dynamic urea bonds. Final evidence of the exchange reactions was revealed by stirring polymer $\mathbf{P 2}$ for $24 \mathrm{~h}$ in aniline at $100^{\circ} \mathrm{C}$. Afterwards, the polymer was completely dissolved, which allowed us to perform SEC measurements (Supplementary Information; Supplementary Figure S6), which revealed a soluble polymer with a molar mass of $M_{\mathrm{n}}=5300 \mathrm{~g} \mathrm{~mol}^{-1}$.

\section{CONCLUSION}

In conclusion, the fabrication of new intrinsic self-healing materials with excellent mechanical properties was reported. The systems are based on crosslinked methacrylates featuring dynamic urea bonds as reversible crosslinking moieties. These functional units can be reversibly opened during thermal treatment due to the utilization of sterically hindered amine groups. To obtain these copolymer networks, urea bonds were formed in situ during photopolymerization. The structural changes in the model compound (opening of the reversible urea bonds) and the corresponding healing mechanism were analyzed using Raman and IR spectroscopy. The self-healing behavior was studied using scratch and bulk-healing tests. Much better scratch-healing behavior compared to the bulk-healing behavior was revealed, which was associated with the reduced contact between sections of the broken specimen during the bulk-healing experiments. Furthermore, the crosslinking density was a crucial parameter for the self-healing performance. Thus, using $5 \%$ crosslinker produced hard materials (E-modulus: $0.34 \mathrm{GPa}$ ) with excellent scratch-healing and acceptable bulk-healing properties at temperatures above $70^{\circ} \mathrm{C}$.

The investigated system is a new representative for smart and stimuli-responsive materials, and further work will be directed toward an application driven investigation. In addition, additional analysis of the molecular behavior will be performed to obtain a detailed overview of the structural changes in the system during external stimulation. The results presented here are the first step toward hard and intrinsically healable polymers, which are usually considered to be an oxymoron. ${ }^{49}$

\section{CONFLICT OF INTEREST}

The authors declare no conflict of interest.

\section{ACKNOWLEDGEMENTS}

We thank the Deutsche Forschungsgemeinschaft (DFG, SPP 1568) for the funding from SPP 1568 (SCHU1229/13-1, HA6306/3-1, DI1517/9-1 and PO563/25-2).

\section{PUBLISHER'S NOTE}

Springer Nature remains neutral with regard to jurisdictional claims in published maps and institutional affiliations.

1 Guimard, N. K., Oehlenschlaeger, K. K., Zhou, J., Hilf, S., Schmidt, F. G. \& Barner-Kowollik, C. Current trends in the field of self-healing materials. Macromol. Chem. Phys. 213, 131-143 (2012).

2 Hager, M. D., Greil, P., Leyens, C., van der Zwaag, S. \& Schubert, U. S. Self-healing materials. Adv. Mater. 22, 5424-5430 (2010).

3 White, S. R., Sottos, N. R., Geubelle, P. H., Moore, J. S., Kessler, M. R., Sriram, S. R., Brown, E. N. \& Viswanathan, S. Autonomic healing of polymer composites. Nature 409, 794-797 (2001).

4 Li, C., Tan, J., Gu, J., Qiao, L., Zhang, B. \& Zhang, Q. Rapid and efficient synthesis of isocyanate microcapsules via thiol-ene photopolymerization in Pickering emulsion and its application in self-healing coating. Compos. Sci. Technol. 123, 250-258 (2016). 
5 Gu, J., Yang, X., Li, C. \& Kou, K. Synthesis of cyanate ester microcapsules via solvent evaporation technique and its application in epoxy resins as a healing agent. Ind. Eng. Chem. Res. 55, 10941-10946 (2016).

6 Garcia, S. J. Effect of polymer architecture on the intrinsic self-healing character of polymers. Eur. Polym. J. 53, 118-125 (2014).

7 Kuhl, N., Bode, S., Hager, M. D. \& Schubert, U. S. Self-healing polymers based on reversible covalent bonds. Adv. Polym. Sci. 273, 1-58 (2016).

8 Maeda, T., Otsuka, H. \& Takahara, A. Dynamic covalent polymers: Reorganizable polymers with dynamic covalent bonds. Prog. Polym. Sci. 34, 581-604 (2009).

9 Rowan, S. J., Cantrill, S. J., Cousins, G. R. L., Sanders, J. K. M. \& Stoddart, J. F. Dynamic covalent chemistry. Angew. Chem. Int. Ed. 41, 598-952 (2002).

10 Chen, X., Dam, M. A., Ono, K., Mal, A., Shen, H., Nutt, S. R., Sheran, K. \& Wudl, F. A Thermally re-mendable cross-linked polymeric material. Science 295, 1698-1702 (2002).

11 Chen, X., Wudl, F., Mal, A. K., Shen, H. \& Nutt, S. R. New thermally remendable highly cross-linked polymeric materials. Macromolecules 36, 1802-1807 (2003).

12 Geitner, R., Kötteritzsch, J., Siegmann, M., Bocklitz, T. W., Hager, M. D. Schubert, U. S., Grafe, S., Dietzek, B., Schmitt, M. \& Popp, J. Two-dimensional Raman correlation spectroscopy reveals molecular structural changes during temperature-induced self-healing in polymers based on the Diels-Alder reaction. Phys. Chem. Chem. Phys. 17, 22587-22595 (2015).

13 Imato, K., Takahara, A. \& Otsuka, H. Self-healing of a cross-linked polymer with dynamic covalent linkages at mild temperature and evaluation at macroscopic and molecular levels. Macromolecules 48, 5632-5639 (2015).

14 Chen, Y., Kushner, A. M., Williams, G. A. \& Guan, Z. Multiphase design of autonomic self-healing thermoplastic elastomers. Nat. Chem. 4, 467-472 (2012).

15 Cordier, P., Tournilhac, F., Soulie-Ziakovic, C. \& Leibler, L. Self-healing and thermoreversible rubber from supramolecular assembly. Nature 451, 977-980 (2008).

16 Tepper, R., Bode, S., Geitner, R., Jäger, M., Görls, H., Vitz, J., Dietzek, B., Schmitt, M., Popp, J., Hager, M. D. \& Schubert, U. S. Polymeric halogen bond based donor systems showing self-healing behavior in thin films. Angew. Chem. Int. Ed. 56, 4047-4051 (2017)

17 Bose, R. K., Hohlbein, N., Garcia, S. J., Schmidt, A. M. \& van der Zwaag, S. Connecting supramolecular bond lifetime and network mobility for scratch healing in poly(butyl acrylate) ionomers containing sodium, zinc and cobalt. Phys. Chem. Chem. Phys. 17, 1697-1704 (2015).

18 Hart, L. R., Hunter, J. H., Nguyen, N. A., Harries, J. L., Greenland, B. W., Mackay, M. E., Colquhoun, H. M. \& Hayes, W. Multivalency in healable supramolecular polymers: the effect of supramolecular cross-link density on the mechanical properties and healing of non-covalent polymer networks. Polym. Chem. 5, 3680-3688 (2014).

19 Nakahata, M., Mori, S., Takashima, Y., Yamaguchi, H. \& Harada, A. Self-healing materials formed by cross-linked polyrotaxanes with reversible bonds. Chem. 1, 766-775 (2016).

20 Burnworth, M., Tang, L., Kumpfer, J. R., Duncan, A. J., Beyer, F. L., Fiore, G. L., Rowan, S. J. \& Weder, C. Optically healable supramolecular polymers. Nature 472 334-337 (2011)

21 Bode, S., Zedler, L., Schacher, F. H., Dietzek, B., Schmitt, M., Popp, J., Hager, M. D. \& Schubert, U. S. Self-healing polymer coatings based on crosslinked metallosupramolecular copolymers. Adv. Mater. 25, 1634-1638 (2013).

22 Kupfer, S., Zedler, L., Guthmuller, J., Bode, S., Hager, M. D., Schubert, U. S., Popp, J., Grafe, S. \& Dietzek, B. Self-healing mechanism of metallopolymers investigated by QM/MM simulations and Raman spectroscopy. Phys. Chem. Chem. Phys. 16, 12422-12432 (2014)

23 Bode, S., Enke, M., Bose, R. K., Schacher, F. H., Garcia, S. J., van der Zwaag, S., Hager, M. D. \& Schubert, U. S. Correlation between scratch healing and rheological behavior for terpyridine complex based metallopolymers. J. Mater. Chem. A 3 , 22145-22153 (2015)

24 Rekondo, A., Martin, R., Ruiz de Luzuriaga, A., Cabanero, G., Grande, H. J. \& Odriozola, I. Catalyst-free room-temperature self-healing elastomers based on aromatic disulfide metathesis. Mater. Horiz. 1, 237-240 (2014).

25 Martin, R., Rekondo, A., Ruiz de Luzuriaga, A., Cabanero, G., Grande, H. J. \& Odriozola, I. The processability of a poly(urea-urethane) elastomer reversibly crosslinked with aromatic disulfide bridges. J. Mater. Chem. A 2, 5710-5715 (2014).

26 Liu, C.-C., Zhang, A.-Y., Ye, L. \& Feng, Z.-G. Self-healing biodegradable poly(urea-urethane) elastomers based on hydrogen bonding interactions. Chin. J. Polym. Sci. 31, 251-262 (2013)

27 Brunsveld, L., Folmer, B. J. B., Meijer, E. W. \& Sijbesma, R. P. Supramolecular polymers. Chem. Rev. 101, 4071-4098 (2001).

28 Hager, M. D., Bode, S., Weber, C. \& Schubert, U. S. Shape memory polymers: past, present and future developments. Prog. Polym. Sci. 49, 3-33 (2015).

29 Lutz, A., van den Berg, O., Van Damme, J., Verheyen, K., Bauters, E., De Graeve, I., Du Prez, F. E. \& Terryn, H. A shape-recovery polymer coating for the corrosion protection of metallic surfaces. ACS Appl. Mater. Interfaces 7, 175-183 (2015).

30 Rivero, G., Nguyen, L.-T. T., Hillewaere, X. K. D. \& Du Prez, F. E. One-pot thermoremendable shape memory polyurethanes. Macromolecules 47, 2010-2018 (2014).

31 Delebecq, E., Pascault, J.-P., Boutevin, B. \& Ganachaud, F. On the versatility of urethane/urea bonds: Reversibility, blocked isocyanate, and non-isocyanate polyurethane. Chem. Rev. 113, 80-118 (2013).

32 Hoff, E. A., Abel, B. A., Tretbar, C. A., McCormick, C. L. \& Patton, D. L. RAFT polymerization of 'splitters' and 'cryptos': exploiting azole- $N$-carboxamides as blocked isocyanates for ambient temperature postpolymerization modification. Macromolecules 49, 554-563 (2016)

33 Ying, H. \& Cheng, J. Hydrolyzable polyureas bearing hindered urea bonds. J. Am. Chem. Soc. 136, 16974-16977 (2014)

34 Chang, J. Y., Do, S. K. \& Han, M. J. A sol-gel reaction of vinyl polymers based on thermally reversible urea linkages. Polymer 42, 7589-7594 (2001).

35 Ying, H., Zhang, Y. \& Cheng, J. Dynamic urea bond for the design of reversible and selfhealing polymers. Nat. Commun. 5, 3218 (2014).

36 Zhang, Y., Ying, H., Hart, K. R., Wu, Y., Hsu, A. J., Coppola, A. M., Kim, T. A., Yang, K., Sottos, N. R., White, S. R. \& Cheng, J. Malleable and recyclable poly(urea-urethane) thermosets bearing hindered urea bonds. Adv. Mater. 28, 7646-7651 (2016).

37 R. Core Team R: A Language and Environment for Statistical Computing (Wien, Austria, 2014).

38 Morhac, M. Peaks: Peaks (2012). https://CRAN.R-project.org/package=Peaks.

39 Becke, A. D. Density-functional thermochemistry. III. The role of exact exchange. J. Chem. Phys. 98, 5648-5652 (1993).

40 Lee, C., Yang, W. \& Parr, R. G. Development of the Colle-Salvetti correlation-energy formula into a functional of the electron density. Phys. Rev. B 37, 785-789 (1988).

41 Ditchfield, R., Hehre, W. J. \& Pople, J. A. Self-consistent molecular-orbital methods. IX. An extended Gaussian-type basis for molecular-orbital studies of organic molecules. J. Chem. Phys. 54, 724-728 (1971)

42 Hehre, W. J., Ditchfield, R. \& Pople, J. A. Self-consistent molecular orbital methods. XII. Further extensions of Gaussian-type basis sets for use in molecular orbital studies of organic molecules. J. Chem. Phys. 56, 2257-2261 (1972).

43 Frisch, M. J., Trucks, G. W., Schlegel, H. B., Scuseria, G. E., Robb, M. A., Cheeseman, J. R., Scalmani, G., Barone, V., Mennucci, B., Petersson, G. A., Nakatsuji, H., Caricato, M., Li, X., Hratchian, H. P., Izmaylov, A. F., Bloino, J., Zheng, G., Sonnenberg, J. L., Hada, M., Ehara, M., Toyota, K., Fukuda, R., Hasegawa, J., Ishida, M., Nakajima, T., Honda, Y., Kitao, O., Nakai, H., Vreven, T., Montgomery, J. A. Jr, Peralta, J. E., Ogliaro, F., Bearpark, M. J., Heyd, J., Brothers, E. N., Kudin, K. N., Staroverov, V. N., Kobayashi, R., Normand, J., Raghavachari, K., Rendell, A. P., Burant, J. C., Iyengar, S. S., Tomasi, J., Cossi, M., Rega, N., Millam, N. J., Klene, M., Knox, J. E., Cross, J. B., Bakken, V., Adano, C., Jaramillo, J., Gomperts, R., Stratmann, R. E., Yazyev, O., Austin, A. J., Cammi, R., Pomelli, C., Ochterski, J. W., Martin, R. L., Morokuma, K., Zakrezewski, V. G., Voth, G. A., Salvador, P., Dannenberg, J. J., Dapprich, S., Daniels, A. D., Farkas, Ö., Foresman, J. B., Ortiz, J. V., Cioslowski, J. \& Fox, D. J. Gaussian 09 (Revision A.02), (Gaussian: Wallingford, CT, USA, 2009).

44 Johnson, R. D. NIST Standard Reference Database Number 101 (2011). http://cccbdb. nist.gov/.

45 Merrick, J. P., Moran, D. \& Radom, L. An evaluation of harmonic vibrational frequency scale factors. J. Phys. Chem. A 111, 11683-11700 (2007)

46 Denissen, W., Rivero, G., Nicolay, R., Leibler, L., Winne, J. M. \& Du Prez, F. E. Vinylogous urethane vitrimers. Adv. Funct. Mater. 25, 2451-2457 (2015).

47 Bode, S., Enke, M., Hernandez, M., Bose, R. K., Grande, A. M., Van der Zwaag, S., Schubert, U. S., Garcia, S. J. \& Hager, M. D. Characterization of self-healing polymers: from macroscopic healing tests to the molecular mechanism. Adv. Polym. Sci. 273, 113-142 (2016)

48 Mezger, T. G. The Rheology Handbook 2nd edn (Vincentz Network: Hannover, Germany, 2006).

49 Hoogenboom, R. Hard autonomous self-healing supramolecular materials-a contradiction in terms? Angew. Chem. Int. Ed. 51, 11942-11944 (2012).

50 Coulibaly, S., Roulin, A., Balog, S., Biyani, M. V., Foster, E. J., Rowan, S. J., Fiore, G. L. \& Weder, C. Reinforcement of optically healable supramolecular polymers with cellulose nanocrystals. Macromolecules 47, 152-160 (2014).

51 Tournilhac, F., Cordier, P., Montarnal, D., Soulie-Ziakovic, C. \& Leibler, L. Self-healing supramolecular networks. Macromol. Symp. 291, 84-88 (2010).

$52 \mathrm{Li}, \mathrm{H}$., Bai, J., Shi, Z. \& Yin, J. Environmental friendly polymers based on schiff-base reaction with self-healing, remolding and degradable ability. Polymer 85, 106-113 (2016).

53 Burattini, S., Greenland, B. W., Merino, D. H., Weng, W., Seppala, J., Colquhoun, H. M., Hayes, W., Mackay, M. E., Hamley, I. W. \& Rowan, S. J. A healable supramolecular polymer blend based on aromatic $\pi-\pi$ stacking and hydrogen-bonding interactions. J. Am. Chem. Soc. 132, 12051-12058 (2010).

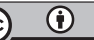

This work is licensed under a Creative Commons Attribution 4.0 International License. The images or other third party material in this article are included in the article's Creative Commons license, unless indicated otherwise in the credit line; if the material is not included under the Creative Commons license, users will need to obtain permission from the license holder to reproduce the material. To view a copy of this license, visit http:// creativecommons.org/licenses/by/4.0/

(C) The Author(s) 2017

Supplementary Information accompanies the paper on the NPG Asia Materials website (http://www.nature.com/am) 